\title{
Capsazepine Protects against Neuronal Injury Caused by Oxygen Glucose Deprivation by Inhibiting $I_{h}$
}

\author{
Alison M. Ray, Ceri D. Benham, Jenny C. Roberts, Catherine H. Gill, Christophe Lanneau, Danniel P. Gitterman, \\ Mark Harries, John B. Davis, and Christopher H. Davies \\ Neurology Centre of Excellence for Drug Discovery, GlaxoSmithKline, Harlow, Essex, CM19 5AW, United Kingdom
}

Cell death mechanisms frequently involve the influx of extracellular calcium through voltage- and ligand-gated ion channels, e.g., the NMDA receptor (Greene, 1999). The vanilloid receptor $\left(\mathrm{VR}_{1}\right)$ is present in regions of the brain (Mezey et al., 2000) that are highly susceptible to neurodegenerative insults, suggesting that this ion channel might contribute to the cellular processes involved in neuronal death. We tested the effects of VR1 ligands in the oxygen glucose deprivation (OGD) model of cell death in organotypic hippocampal slice cultures. The $\mathrm{VR}_{1}$ agonist capsaicin at concentrations that are selective for $\mathrm{VR}_{1}$ did not affect cell viability per se or the extent of neurodegeneration induced by the $0 G D$ insult. In contrast, the $V_{1}$ antagonist capsazepine $(0.1-10 \mu \mathrm{M})$ significantly reduced the amount of OGD-induced cell death. However, capsazepine was still neuroprotective in slices prepared from $\mathrm{VR}_{1}$ knock-out mice, which exhibited the same degree of neurodegeneration to that observed in slices prepared from wild-type mice, excluding the possibility that it afforded neuroprotection through inhibition of $\mathrm{VR}_{1}$. Instead, capsazepine inhibited the hyperpolarization-activated nonspecific cation channel generated current $I_{h}$ in a concentration range similar to that which was neuroprotective. Furthermore, the specific $I_{h}$ blocker ZD-7288 was also neuroprotective, mirroring the effects of capsazepine, in that it was effective at preventing cell death when applied either during or after the OGD insult. These results demonstrate that capsazepine affords neuroprotection through inhibition of $I_{h}$ rather than inhibition of $\mathrm{VR}_{1}$.

Key words: capsazepine; vanilloid; organotypic slice; neuroprotection; oxygen/glucose deprivation; HCN channels; $I_{h}$

\section{Introduction}

The cloning of the vanilloid receptor $\left(\mathrm{VR}_{1}\right)$, concomitant development of $\mathrm{VR}_{1}$-selective ligands (i.e., selective agonists, antagonists, radioligands, and monoclonal antibodies), and generation of mice genetically deficient for $\mathrm{VR}_{1}$ have provided a major impetus toward the understanding of the physiological functions of this $\mathrm{Ca}^{2+}$-permeable, nonselective cation channel. In particular, these approaches have been invaluable in demonstrating that $\mathrm{VR}_{1}$ protein is heavily expressed in sensory neurons and that this channel plays an important role in sensory nociceptive signaling (Caterina and Julius, 2001).

However, the more widespread distribution of both $\mathrm{VR}_{1}$ mRNA and protein in areas such as the hippocampus, striatum, hypothalamus, and cerebellum in both human and rat brain has suggested additional functional roles for this channel (Sasamura and Kuraishi, 1999; Hayes et al., 2000; Mezey et al., 2000) in physiological processes such as satiety, cognition, and motor control (Szallasi et al., 1995). Such a concept is supported by the discovery that a number of lipid molecules [e.g., anandamide and sn-2 arachidonylglycerol (Smart and Jerman, 2000)], which are present in the CNS and which can be upregulated or downregulated in line with the level of synaptic activity (Stella et al., 1997),

Received July 2, 2003; revised July 2, 2003; accepted Sept. 10, 2003.

We acknowledge D. E. Owen and S. Vesce for early work that initiated these studies.

Correspondence should be addressed to Alison M. Ray, Department of Neurology Research, GlaxoSmithKline, Third Avenue, Harlow, Essex, CM19 5AW, UK. E-mail: alison_m_ray@gsk.com.

Copyright $\odot 2003$ Society for Neuroscience $\quad$ 0270-6474/03/2310146-08\$15.00/0 activate $\mathrm{VR}_{1}$. That this channel is permeable to $\mathrm{Ca}^{2+}$ also raises the possibility that it may be involved in neurodegenerative disease states. In this respect, both capsaicin and resiniferatoxin elevate intracellular free calcium and cause nuclear membrane disruption and death in cells that express $\mathrm{VR}_{1}$ (Olah et al., 2001; Grant et al., 2002). Furthermore, alterations in environmental cues such as acid $\mathrm{pH}$ and heat that modulate $\mathrm{VR}_{1}$, and occur in response to damaging insults to the brain, may exacerbate any neurodegenerative role that this receptor might play. This is particularly pertinent to cerebral ischemia in which extracellular acidification combined with excitatory amino acid release results in increased anandamide synthesis (Hansen et al., 1995) to levels that will activate $\mathrm{VR}_{1}$ and lead to proapoptotic injury as described in a human neuroblastoma cell line (Maccarrone et al., 2000a,b). Given these observations, we were interested to examine whether or not $\mathrm{VR}_{1}$ contributes to neuronal cell death in intact neuronal circuits. The model system we chose to study was oxygen glucose deprivation (OGD)-induced cell death in organotypic hippocampal slices.

\section{Materials and Methods}

All procedures using animal tissues were performed using standard approved home office protocols.

Autoradiographic binding studies with $\left[{ }^{3} H\right]$ resiniferatoxin. Wild-type $+/+$ and $\mathrm{VR}_{1}$ knock-out mice -/- [postnatal day 21 (P21)] were killed by decapitation. The brains were rapidly removed, frozen, stored at $-80^{\circ} \mathrm{C}$, and subsequently cut into $20 \mu \mathrm{m}$ frozen coronal brain sections. 
The sections were thaw mounted onto gelatin-coated slides and stored at $-80^{\circ} \mathrm{C}$ until time of assay.

After equilibration at room temperature, the sections were incubated in assay buffer containing the following (in $\mathrm{mM}$ ): $5 \mathrm{KCl}, 5.8 \mathrm{NaCl}, 0.75$ $\mathrm{CaCl}_{2}, 2 \mathrm{MgCl}_{2}, 320$ sucrose, and 10 HEPES, pH 7.4, containing $1\left[{ }^{3} \mathrm{H}\right]$ resiniferatoxin $\left(\left[{ }^{3} \mathrm{H}\right] \mathrm{RTX}\right)$ (specific activity, 30-60 Ci/mmol; NEN, Boston, MA) for $60 \mathrm{~min}$. Nonspecific binding was defined by the addition of $1 \mu \mathrm{M}$ unlabelled resiniferatoxin.

After incubation, the sections were washed three times for $10 \mathrm{~min}$ in the assay buffer at a temperature of $4^{\circ} \mathrm{C}$, briefly dipped into distilled water at $4^{\circ} \mathrm{C}$ to remove buffer salts, and allowed to dry in a stream of cool air. The sections were then apposed to ${ }^{3} \mathrm{H}$-Hyperfilm for 5 weeks at $4^{\circ} \mathrm{C}$. Adjacent sections to those used for autoradiography were stained with cresyl fast violet to permit anatomical identification of brain regions. After exposure, the sections were dipped in LM-1 nuclear emulsion to permit cellular localization of the $\left[{ }^{3} \mathrm{H}\right]$ resiniferatoxin binding sites. After 15 weeks of exposure to emulsion, the sections were developed and stained with cresyl fast violet. Images were captured from the autoradiographic film using MCID image analysis software (Interfocus, Cambridge, UK).

Organotypic hippocampal slice culture preparation. Organotypic hippocampal slice cultures were prepared using the method of Stoppini et al. (1991). Seven- to 8-d-old Sprague Dawley rat pups were killed by cervical dislocation and decapitated, and the hippocampi were dissected out. Using a McIlwain tissue chopper, $400-\mu \mathrm{m}$-thick hippocampal slices were cut and placed into ice-cold growth medium consisting of 50\% minimum essential medium (MEM), 25\% HBSS, 25\% heat-inactivated horse serum, $5 \mathrm{mg} / \mathrm{ml}$ glucose, and $1 \mathrm{~mm}$ glutamine. Slices with complete dentate and CA3 and CA1 areas were placed onto semiporous Millicell-CM inserts (three per membrane) and transferred to six-well plates containing $1.2 \mathrm{ml}$ of growth medium. Cultures were maintained in $95 \%$ air $-5 \%$ $\mathrm{CO}_{2}$ at $37^{\circ} \mathrm{C}$. Medium was changed every $4 \mathrm{~d}$, and experiments were performed after 12-14 d in vitro. For mouse cultures, we used the same protocol as for the rat slice culture preparation, except that P6 pups were used and experiments were performed after 7-9 d in vitro. The $\mathrm{VR}_{1}$ knock-out mice were prepared as described previously (Davis et al., 2000).

Oxygen glucose deprivation. For OGD experiments, the culture inserts were transferred into serum-free medium (SF) with or without compound as appropriate for $1 \mathrm{hr}$ before the insult. They were then placed in deoxygenated glucose-free medium and sealed under 95\% $\mathrm{N}_{2}-5 \% \mathrm{CO}_{2}$ in an anaerobic chamber equilibrated to $37^{\circ} \mathrm{C}$ and $100 \%$ humidity (Ray et al., 2000). After 40-45 min of OGD (mouse organotypics, $35 \mathrm{~min}$ ), cultures were removed from the chamber, and the inserts were returned to serum-free medium saturated with $95 \%$ air $-5 \% \mathrm{CO}_{2}$ containing 6 $\mu \mathrm{l} / \mathrm{ml}$ propidium iodide (PI). Compound remained present throughout the duration of the experiment until analysis $23 \mathrm{hr}$ later.

Statistical analysis. OGD-induced cell death was assayed directly in unfixed cultures using a $5 \times$ lens under an inverted microscope (Zeiss, Oberkochen, Germany) equipped for fluorescence detection. Matching PI fluorescence and transmitted light images of each whole slice were recorded, and the amount of cell death in matched control and compound-treated cultures were analyzed using NIH Image software (version 1.62). The area of the cell body layer in the hippocampal CA1 area was traced from the bright-field image and superimposed over the PI image. Results were then expressed as the percentage (mean \pm SEM) of the total CA1 area expressing PI fluorescence. Statistical analysis was determined by ANOVA.

Drug application. Stock solutions of compounds were made up in dimethylsulfoxide (DMSO) (Sigma, St. Louis, MO) at $10 \mathrm{~mm}$. The final concentration of DMSO for any drug treatment was $0.1 \%$, and control groups included $0.1 \%$ DMSO in all experiments. Before OGD, cultures were placed in SF containing 75\% MEM, 25\% HBSS, $5 \mathrm{mg} / \mathrm{ml}$ glucose, and $1 \mathrm{~mm}$ glutamine for $1 \mathrm{hr}$. Compound concentrations were made up from stock solutions as appropriate.

Electrophysiological recordings. Synaptic activity was recorded using either whole-cell patch-clamp or extracellular single-electrode or multielectrode array (MEA) recording approaches. In all recording configurations, slices were bathed in warmed $\left(32-37^{\circ} \mathrm{C}\right)$, perfusing $(1-4 \mathrm{ml} / \mathrm{min})$ artificial CSF (aCSF) containing the following (in $\mathrm{mm}$ ): $124 \mathrm{NaCl}, 3 \mathrm{KCl}$, $26 \mathrm{NaHCO}_{3}, 1.25 \mathrm{NaH}_{2} \mathrm{PO}_{4}, 2 \mathrm{CaCl}_{2}, 1 \mathrm{MgSO}_{4}$, and 10 D-glucose (bubbled with $95 \% \mathrm{O}_{2}-5 \% \mathrm{CO}_{2}$ ).

Whole-cell patch-clamp recordings were made under visual guidance using an Olympus Optical (Tokyo, Japan) BX50WI upright microscope. Microelectrodes (5-8 M $\Omega$ ) connected to an Axopatch 200B amplifier (Axon Instruments, Foster City, CA) were filled with $135 \mathrm{~mm}$ K-gluconate, 10 mM $\mathrm{MgCl}_{2}$, 10 mm HEPES, 2 mM Mg ATP, 1 mm EGTA, $0.3 \mathrm{~mm} \mathrm{Na}$ GTP, $0.1 \mathrm{~mm} \mathrm{CaCl}_{2}$, pH 7.2, 290-295 mOsm. Series resistances were compensated at $80 \%$ with a lag of $8 \mu \mathrm{sec}$. Cell viability was assessed throughout the course of experiments via measurement of cell input resistance. Patch-clamp data were filtered at $5 \mathrm{kHz}$, digitized at 20 $\mathrm{kHz}$, and stored on a personal compauter hard disk drive for offline analysis using Minianalysis software and Clampfit 8.2 (Axon Instruments).

Extracellular recordings were made from individual hippocampal subfields using aCSF-filled glass microelectrodes (1-2 M $\Omega$ ). For evoked responses, concentric bipolar stimulating electrodes were placed to stimulate the Schaffer collaterals at the CA3 to CA1 border, and glass recording electrodes filled with aCSF were placed in the center of the CA1 stratum pyramidale. Constant current pulses were applied in $100 \mu \mathrm{A}$ increments until a maximum response was obtained.

For spontaneous extracellular activity, recordings were made simultaneously from all subfields of hippocampal slices using a 64 electrode planar MEA purchased from MultiChannel Systems (Reutlingen, Germany). A small piece of semiporous membrane bearing the hippocampal slice was cut out of the culture well using a scalpel blade. This was positioned slice down onto an MEA, which had been coated previously using $5 \mu \mathrm{l}$ of a solution comprising $1 \mathrm{~cm}^{2}$ cellulose nitrate filter paper dissolved in $10 \mathrm{ml}$ of methanol. The final orientation of the slice with respect to the electrodes was achieved with the aid of a Zeiss Stemi SV6 microscope. The MEA recording chamber was then immediately flooded with $1 \mathrm{ml}$ of aCSF, and a photographic image was taken of the electrode positions beneath the hippocampal subfields (DC300 digital camera; Leica, Nussloch, Germany). MEA extracellular recordings were made from all subfields of the slice using the procedures outlined previously (Egert et al., 1998). MEA data were sampled at $5 \mathrm{kHz}$, stored on hard disk or CD-R, and analyzed offline using Multi Channel Systems and pClamp 9 (Axon Instruments) and Neuroexplorer (Plexon Instruments) software.

\section{Results}

\section{Effect of capsaicin on OGD-induced cell death}

Recent localization studies demonstrate expression of $\mathrm{VR}_{1}$ immunoreactivity and $\mathrm{VR}_{1}$ mRNA in many regions of the rodent brain, including the cortex and hippocampus (Mezey et al., 2000). Because $\mathrm{VR}_{1}$ provides a $\mathrm{Ca}^{2+}$ influx pathway that might be activated in pathophysiological conditions, we hypothesized that agonists and antagonists of $\mathrm{VR}_{1}$ might have neurotoxic and neuroprotective effects, respectively, under conditions of OGD. Before being subjected to the OGD insult, organotypic hippocampal cultures were grown for 12-14 d and examined for signs of cell death. The $\mathrm{VR}_{1}$ full agonist capsaicin $(10 \mu \mathrm{M})$, applied for $24 \mathrm{hr}$ to control cultures, produced no toxic effect, as evaluated by the absence of any change in the low level of PI staining observed in these untreated slices (data not shown). Likewise, capsaicin (10 $\mu \mathrm{M}$ ) applied from $1 \mathrm{hr}$ before OGD through the OGD period and up to the $24 \mathrm{hr}$ post-OGD assessment time point did not affect the extent of cell death induced by the OGD insult (data not shown).

\section{Effect of capsazepine on OGD-induced cell death}

Next we tested the ability of the $\mathrm{VR}_{1}$ antagonist capsazepine to protect against the OGD insult. Application of capsazepine from $1 \mathrm{hr}$ before and throughout the OGD insult significantly reduced the magnitude of PI staining measured $24 \mathrm{hr}$ after the OGD insult (Fig. 1A). This capsazepine-induced neuroprotection was concentration dependent. Thus, $100 \mathrm{~nm}$ capsazepine reduced CA1 cell death by $34 \pm 8 \%$, whereas $10 \mu \mathrm{M}$ produced almost complete 
A
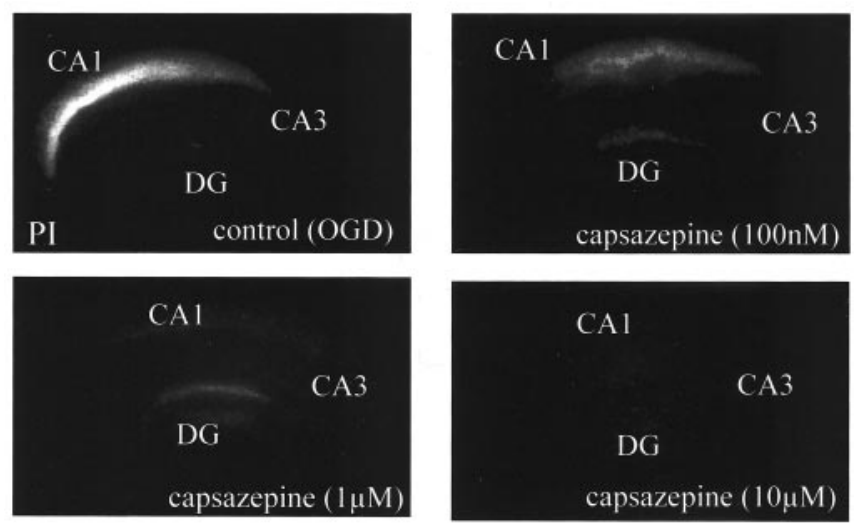

B

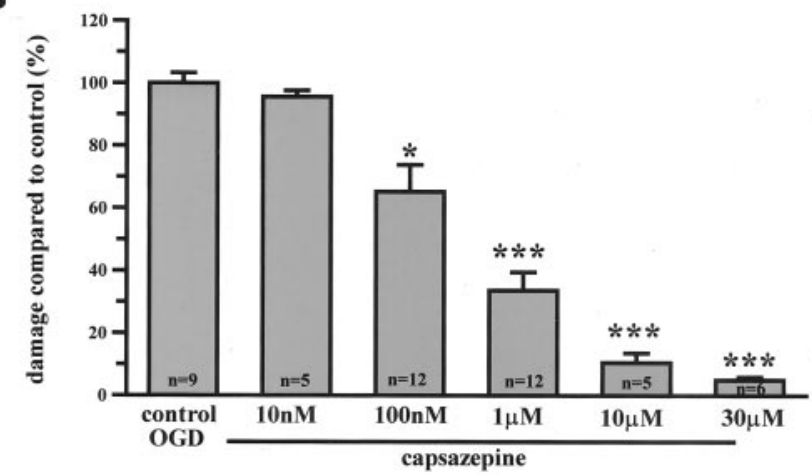

Figure 1. Concentration-dependant reduction in PI staining by capsazepine in organtypic brain slices. A, Propidium iodide-stained slice cultures after 45 min 0GD imaged at $24 \mathrm{hr}$ after insult. Control OGD, $100 \mathrm{~nm}$ capsazepine, $1 \mu \mathrm{m}$ capsazepine, $10 \mu \mathrm{m}$ capsazepine. B, Capsazepine protects hippocampal CA1 neurons from $0 G D$-induced cell death in a concentration-dependent manner. Data are mean \pm SEM. ${ }^{*} p<0.05{ }^{* * *} p<0.0005$. DG, Dentate gyrus.

protection (Fig. $1 B$ ), potency in line with the activity of capsazepine at rat $\mathrm{VR}_{1}$ (Jerman et al., 2000; McIntyre et al., 2001). Vehicle controls produced no alteration in OGD-induced PI staining.

To determine whether the neuroprotection afforded by capsazepine in slice viability experiments corresponded to functional neuroprotection, we investigated whether capsazepine also reversed the electrophysiological deficits induced by the OGD insult. As illustrated in Figure 2, the maximum amplitude of population spikes evoked in stratum pyramidale of area CA1 in response to stimulation of the Schaffer collateral commissural pathway was dramatically reduced $24 \mathrm{hr}$ after the OGD insult compared with that recorded in untreated control slices. In contrast, population spikes in slices that were exposed to OGD in the presence of capsazepine were not significantly different from control $(p>0.05)$ (Fig. 2A). This preservation of synaptic activity was also evident in multi-electrode array recordings in which spontaneous activity present in control slices was eliminated in OGD slices but preserved in slices treated with capsazepine (Fig. 2 B).

\section{Post OGD treatment with capsazepine}

Although capsazepine afforded clear functional protection of hippocampal synaptic activity when used as a continuous application covering the period from $1 \mathrm{hr}$ before the OGD insult right up to the $23 \mathrm{hr}$ post-OGD assessment point, we were interested to ascertain whether more restricted applications also proved neuroprotective. To do this, two strategies were used: (1) capsazepine

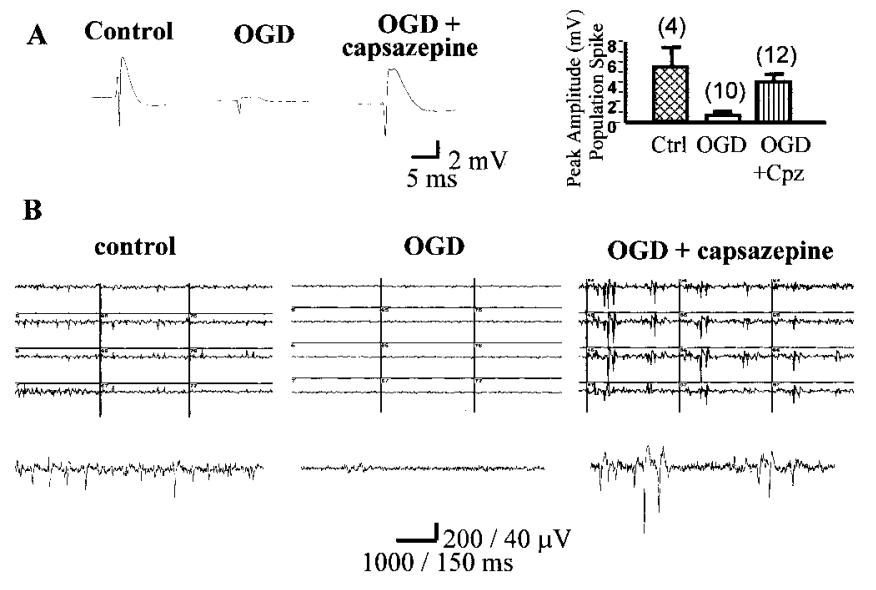

Figure 2. Functional neuroprotection with capsazepine. $A$, Maximum amplitude population spikes, recorded in stratum pyramidale of area CA1 using a $3 \mathrm{~m} \mathrm{NaCl}$ filled microelectrode, from a control slice (no OGD insult), a slice that has received OGD, and an OGD plus capsazepine (10 $\mu \mathrm{m})$-treated slice. The bar graph shows pooled data for the peak amplitude of the population spike evoked in these three populations of slices, with numbers of slices in parentheses. OGDtreated slices show a reduction in EPSP amplitude, and this is prevented by capsazepine. $B$, Extracellular population spike activity recorded from area CA1 of hippocampal organotypic slices. Three grids show representative 1 sec sweeps from 12 electrodes beneath area CA1. A single trace is shown below each grid on an enlarged scale. The left shows the level of spontaneous activity present in a naive control slice. OGD insult (middle) virtually abolishes all firing, whereas pretreatment with capsazepine ( $10 \mu \mathrm{m}$; $(\mathrm{pz})$ administered $1 \mathrm{hr}$ before $0 \mathrm{GD}$ affords a clear preservation of neuronal activity recorded immediately after insult (right).

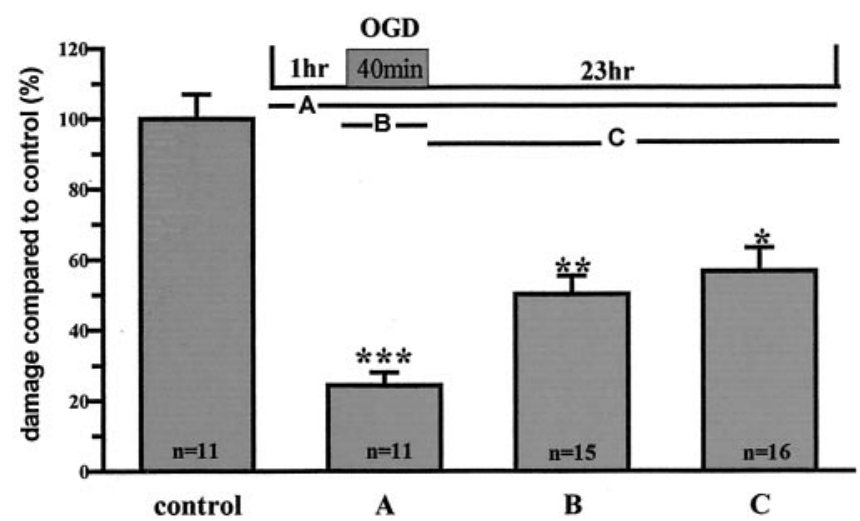

Figure 3. Capsazepine is still neuroprotective if added after 0GD. Capsazepine (10 $\mu \mathrm{m}$ ) was added to the cultures at three different time points: before $0 G D$ for $1 \mathrm{hr}$, remaining throughout until analysis at $24 \mathrm{hr}(A)$, during the $0 \mathrm{GD}$ phase only $(B)$, and after $O G D$ only, remaining until analysis $23 \mathrm{hr}$ later ( $C$. Results show that there was significant protection in all cases, with the greatest effect seen with the standard pretreatment. Data are mean \pm SEM. ${ }^{*} p<0.05$; ${ }^{* *} p<$ $0.005 ;{ }^{* * *} p<0.0005$.

(10 $\mu \mathrm{M})$ was applied just for the period of the OGD insult, and (2) capsazepine $(10 \mu \mathrm{M})$ was applied starting just after the OGD insult and continuing up to the $23 \mathrm{hr}$ post-OGD assessment point. In both experiments, significant neuroprotection was measured using propidium iodide staining, although the absolute magnitude of protection was slightly lower than that when a pretreatment drug regimen was used (Fig. 3). Regardless of this, these data suggest that capsazepine has protective actions both during the OGD insult and in the period after OGD.

\section{OGD-induced cell death in $\mathrm{VR}_{\mathbf{1}}$ knock-out mice}

Given that (1) capsazepine has been reported to inhibit a number of ion channels other than $\mathrm{VR}_{1}$ and (2) the $\mathrm{VR}_{1}$ agonist capsaicin 
A

VR-1 +/+Wildtype
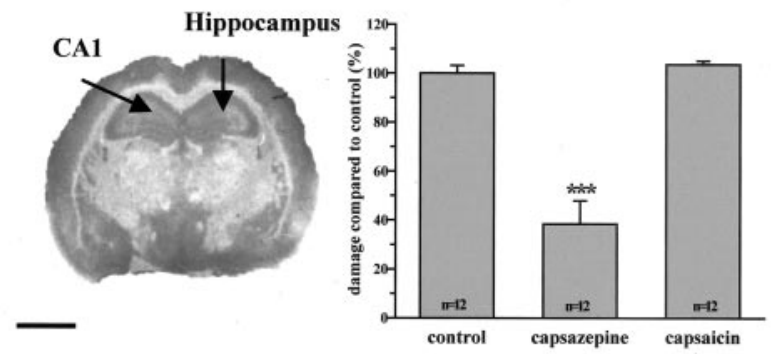

VR-1 -/- Knockout

B

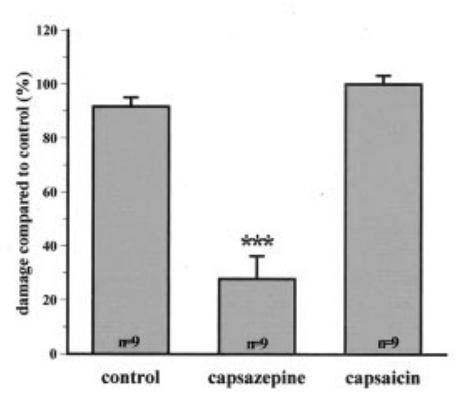

control (OGD)
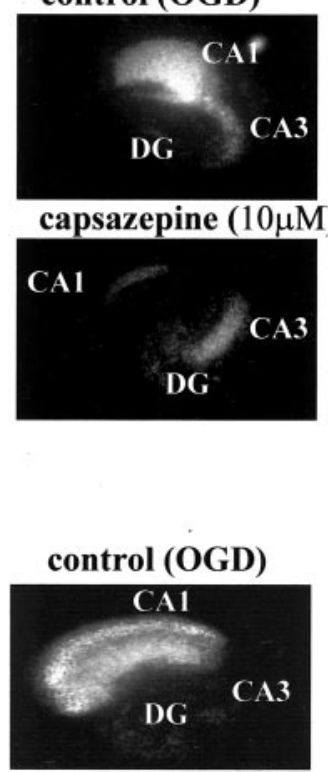

capsazepine $(10 \mu \mathrm{M})$

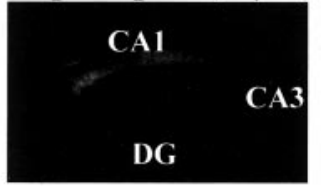

$77 \pm 3 \%$ ) (Fig. 4). These data indirectly increased the possibility that capsazepine was having its neuroprotective effects through mechanisms other than $\mathrm{VR}_{1}$ antagonism.

To test this hypothesis, we next examined whether capsazepine prevented OGD-induced neuronal cell death in hippocampal slice cultures obtained from $\mathrm{VR}_{1}-/-$ mice. As in rat hippocampus, capsaicin had no effect on OGD-induced cell death in either $\mathrm{VR}_{1}+/+$ or $\mathrm{VR}_{1}-/-$ slices (Fig. $4 A, B$ ). However, $10 \mu \mathrm{M}$ capsazepine administered from $1 \mathrm{hr}$ before OGD and throughout the insult until the $23 \mathrm{hr}$ post-OGD assessment time point afforded similar levels of neuroprotection in both $\mathrm{VR}_{1}+/+$ and $\mathrm{VR}_{1}-/-$ slice cultures to that observed in rat hippocampal slices. Together, these results provide convincing evidence that $\mathrm{VR}_{1}$-activated cellular processes are not involved in OGD-induced neurodegeneration in the hippocampus and suggest that the neuroprotective mechanism of capsazepine operates via an alternative process to simple blockade of $\mathrm{VR}_{1}$.

Capsazepine neuroprotection: an action on other receptors or ion channels?

Given these data, we next examined whether any of the other pharmacological actions that have been described for capsazepine could account for its neuroprotective effects. In a first series of experiments, we examined whether capsazepine

Figure 4. Capsazepine is still protective against OGD-induced cell death in VR ${ }_{1}$ knock-out mice cultures. Distribution of spect sinferatoxin binding in the brain of $\mathrm{VR}_{1}$ wild-type and knock-out mice $(A, B$, respectively). Scale bar, $2 \mathrm{~mm}$. Note the lar reduction in binding seen in the knock-out brain compared with the wild type. $A$, Control damage in $\mathrm{VR}_{1}+/+$ mice is similar to that in $\mathrm{VR}_{1}-/-$ mice $(B)$, indicating that $\mathrm{VR}_{1}$ is not required for $\mathrm{OGD}$-induced cell death. Capsaicin has no effect in either $\mathrm{VR}$ $+/+$ mice or $\mathrm{VR}_{1}-/-$ mice, whereas capsazepine protects against $C A 1$ damage in cultures from both $\mathrm{VR}_{1}+/+$ and $\mathrm{VR}_{1}-/-$ mice. ${ }^{* * *} p<0.0005$ (middle graphs). Images on the right show PI staining in slice cultures from either control OGD or OGD and capsazepine $(10 \mu \mathrm{M})$. DG, Dentate gyrus.

did not in its own right cause neurotoxicity, it was possible that capsazepine was having its neuroprotective action through mechanisms other than $\mathrm{VR}_{1}$ antagonism. To test this hypothesis, we examined whether genetic elimination of $\mathrm{VR}_{1}$ decreased the susceptibility of $\mathrm{VR}_{1}-/-$ (Davis et al., 2000) organotypic hippocampal slices to damage by OGD insult.

Initially, we established that $\mathrm{VR}_{1}$ had been knocked out by comparing the pattern of $\left[{ }^{3} \mathrm{H}\right] \mathrm{RTX}$ binding in $\mathrm{VR}_{1}+/+$ with that in $\mathrm{VR}_{1}-/-$ brain. Autoradiographical analysis using this radioligand produced a strong signal compared with nonspecific binding in all neuronal layers of the hippocampus from $\mathrm{VR}_{1}+/+$ animals $(n=3)$ (Fig. $4 A$ ). Examination of the CA1 region at higher magnification revealed silver grains distributed over stratum pyramidale, oriens, and radiatum (data not shown). In contrast, sections of $\mathrm{VR}_{1}-/-$ tissue showed levels of $\left[{ }^{3} \mathrm{H}\right] \mathrm{RTX}$ binding that were little different from nonspecific binding $(n=3)$ (Fig. $4 B$ ). These results confirmed that $\mathrm{VR}_{1}$ protein was widely distributed in all subfields of the hippocampus and that this was absent in $\mathrm{VR}_{1}-/-$ brain.

We next proceeded to explore the functional effects of $\mathrm{VR}_{1}$ ligands on OGD-induced cell death in $\mathrm{VR}_{1}-/-$ organotypic hippocampal slices. To do this, we first needed to reduce the period of OGD in mouse slice cultures to $35 \mathrm{~min}$ to match the level of CA1 neuronal cell death to that produced by $45 \mathrm{~min}$ OGD in rat slice cultures. This aside, it was interesting to establish that the extent of control damage in $\mathrm{VR}_{1}-/$ - hippocampal slices was not significantly different from that in $\mathrm{VR}_{1}+/+$ slices $(84 \pm 3$ vs

affected both ionotropic and metabotropic glutamate receptors (mGluRs) because antagonism of these receptors has been widely reported to afford functional neuroprotection in vitro. As illustrated in Figure $5 A$, capsazepine had no effect on the frequency or amplitude of spontaneous AMPA or $\mathrm{GABA}_{\mathrm{A}}$ receptor-mediated postsynaptic currents recorded in organotypic slice cultures. Furthermore, capsazepine had no effect on either bicuculline (10 $\mu \mathrm{M})$ induced epileptiform activity $(n=6)$ (Fig. $5 B)$, which is dependent on activation of both NMDA and AMPA receptors, or mGluR-dependent synchronized population bursting induced by application of the group I mGluR agonist $(R S)-3,5$ dihydroxyphenylglycine (DHPG) $(20 \mu \mathrm{M})$ (frequency of bursting and peak amplitude of individual bursts in the absence and presence of capsazepine were $16.2 \pm 2.6$ and $17.4 \pm 1.4 \mathrm{~Hz}$ and $208 \pm$ 13 and $205 \pm 16$ pA, respectively; $n=3$ ) (Fig. 5C).

In a second series of experiments, we examined whether capsazepine affected TTX-sensitive voltage-gated sodium channels in organotypic hippocampal slices because inhibition of these channels affords complete neuroprotection to OGD. In three experiments, capsazepine did not affect voltage-gated sodium currents such that the peak amplitude of the $\mathrm{Na}^{+}$current in response to a $20 \mathrm{mV}$ depolarizing step was $4143 \pm 132 \mathrm{pA}$ in control medium as opposed to $4457 \pm 141 \mathrm{pA}$ in the presence of capsazepine (Fig. 5D).

In a third series of experiments, we examined the unlikely possibility that the well documented antagonism of nicotinic acetylcholine receptors by capsazepine (Liu and Simon, 1997) ac- 

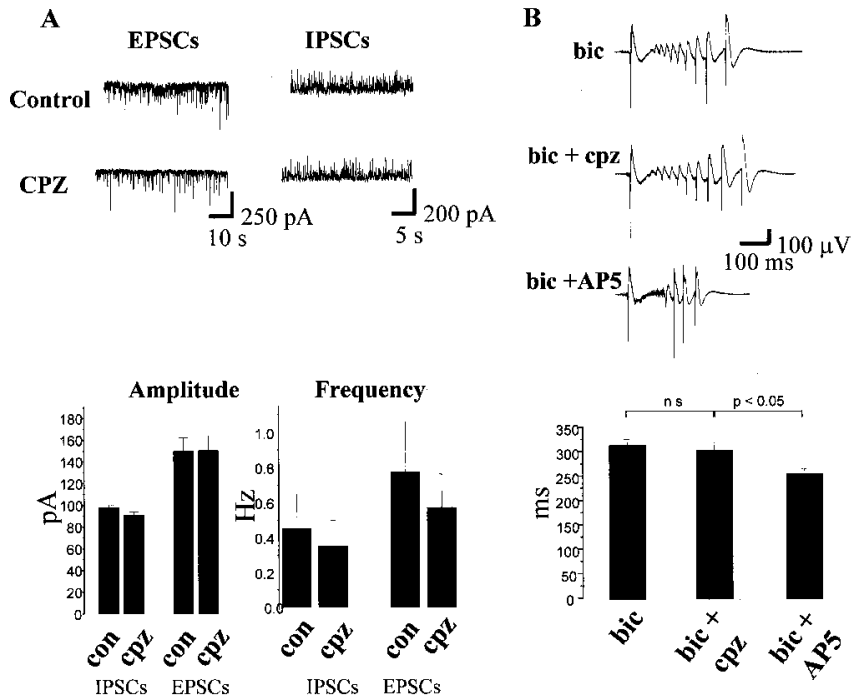

C

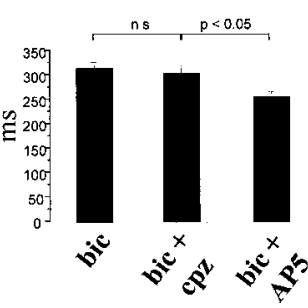

D

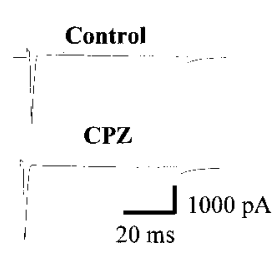

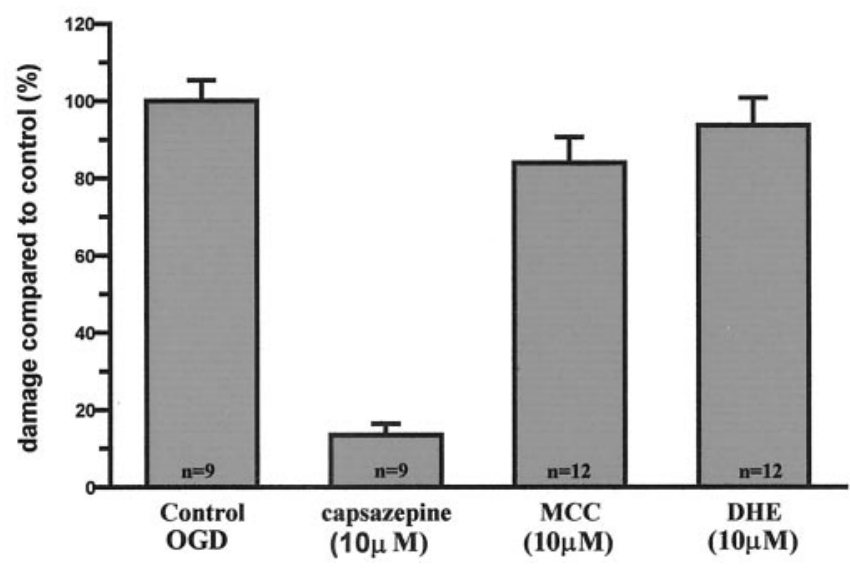

Figure 6. Nicotinic receptor antagonists are not neuroprotective against OGD-induced cell death. Effect of the broad-spectrum nAChR antagonist dihydro- $\beta$-erythroidine (10 $\mu \mathrm{m}$; DHE) and the $\alpha 7$ nAChR-selective antagonist $\alpha$-methlylcaconitine (10 $\mu \mathrm{M}$; MCC) on 0GD-induced cell death in organotypic slice cultures. $n=12$ each group. Data are mean \pm SEM and normalized to control.

rons tested, capsazepine $(10 \mu \mathrm{M})$ produced a $42.3 \pm 2.8 \%$ inhibition of $I_{h}(n=3)$, whereas the specific $I_{h}$ inhibitor ZD-7288 at the same concentration afforded a $9.26 \pm 5.3 \%$ block $(n=3)$.

Given these findings and that capsazepine produced almost complete inhibition of OGD-induced cell death at $10 \mu \mathrm{M}$, we were interested to examine whether ZD-7288 was also able to prevent OGD-induced cell damage. Application of ZD-7288 from $1 \mathrm{hr}$ before and throughout the OGD insult significantly reduced the magnitude of PI staining measured $24 \mathrm{hr}$ after the OGD insult (Fig. 7). This effect was concentration dependent such that $100 \mathrm{~nm}$ ZD-7288 reduced CA1 cell death by $19.14 \pm$ $4.6 \%$, whereas $1 \mu \mathrm{M}$ produced almost complete protection, with vehicle controls producing little or no effect. To further characterize this neuroprotective effect of ZD-7288, we examined whether functional neuroprotection was obtained by investigating whether this compound also reversed the electrophysiological deficits induced by the OGD insult. As illustrated in Figure 7, ZD-7288 significantly reversed the reduction in maximum population spike amplitude that is observed $24 \mathrm{hr}$ after the OGD insult in untreated control slices.

Although these results closely paralleled those of capsazepine treatment, we wanted to confirm that ZD-7288 was also capable of providing neuroprotection when it was applied after the OGD insult because this was another activity exhibited by capsazepine. To do this, ZD-7288 (10 $\mu \mathrm{M})$ was applied starting just after the OGD insult and continuing up to the $23 \mathrm{hr}$ post-OGD assessment point. As predicted, if capsazepine was affording neuroprotection through inhibition of $I_{h}, Z D-7288$, when applied after the OGD insult, prevented the increase in propidium iodide staining that was observed in control slices.

\section{Discussion}

In this study, we showed that $\mathrm{VR}_{1}$ protein is abundantly expressed in the hippocampus and that, in a hippocampal slice culture model using both rat and mouse organotypic slices, capsaicin is not neurotoxic. Capsazepine on the other hand is a potent neuroprotective agent against OGD-induced damage. However, this neuroprotection is not via an action on $\mathrm{VR}_{1}$. To gain insight into the mechanism of action of capsazepine, we investigated its actions on other receptors and channels within the slice 

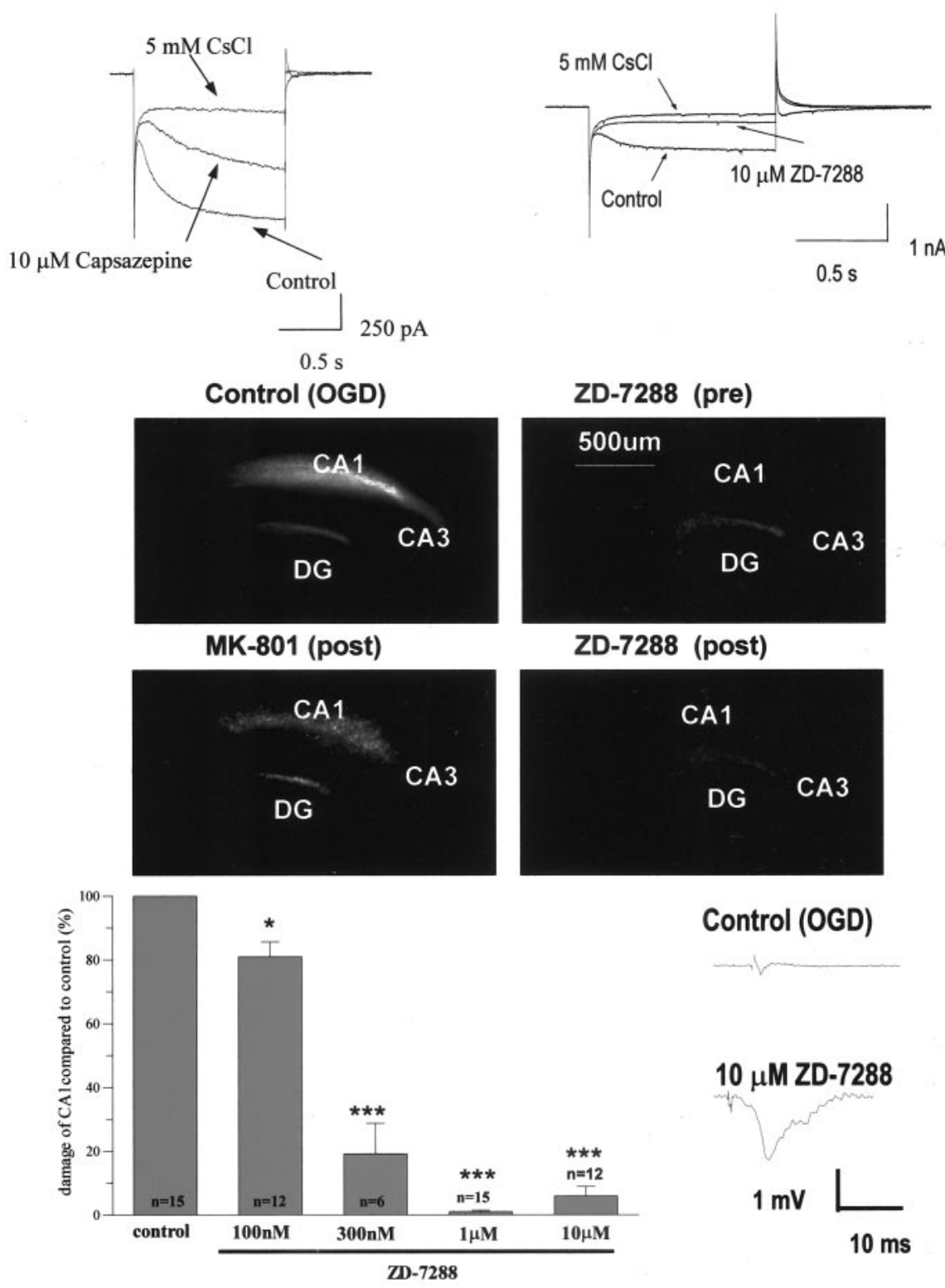

Figure 7. Capsazepine inhibits $I_{h}$, and the specific $I_{h}$ blocker ZD-7288 is neuroprotective against OGD-induced cell death. $A$, Sample traces from whole-cell patch-clamp recordings of hyperpolarized activated cation current. Left shows the significant inhibitory effect of capsazepine, and the right shows near-complete block of the current by the specific $I_{h}$ blocker ZD-7288. In each panel, responses in the presence of $\mathrm{CsCl}$, which abolishes the current, are included as a reference. $B$, Pl images of organotypic hippocampal slice cultures treated with vehicle (Control), ZD-7288 (1 $\mu \mathrm{M})$, or MK-801 (positive control) (10 $\mu \mathrm{M})$. Compound was given either $1 \mathrm{hr}$ before $0 G \mathrm{G}$ or immediately after OGD. Images were taken $24 \mathrm{hr}$ after insult. C, Dose-response data for ZD-7288. ${ }^{*} p<0.05 ;{ }^{* * *} p<0.0005$. Data are mean \pm SEM and normalized to control. $D$, Typical field EPSPs recorded in the CA1 region of the hippocampus. The presence of ZD-7288 substantially reversed the reduction in amplitude of responses in slices subjected to OGD.

and discuss further potential targets in which capsazepine may have an action.

\section{$\mathrm{VR}_{1}$ agonist effects in slice cultures}

In our experiments, capsaicin showed no deleterious effects on either naive slice cultures or cultures exposed to OGD in the presence of capsaicin. In contrast, in other purely cell-based systems, agonists of $\mathrm{VR}_{1}$ have induced apoptotic mechanisms resulting in cell death (Maccarrone et al., 2000a). This apoptotic cell death is usually linked to an increase in internal calcium levels and activation of certain proteases (Chard et al., 1995). The reason for this difference is not clear. One possibility is that, in organotypic slices, the expression of $\mathrm{VR}_{1}$ on individual neurons may be so low that any intracellular rise in $\mathrm{Ca}^{2+}$ is easily buffered, by intracellular $\mathrm{Ca}^{2+}$ binding proteins, to a level that is below that which is neurotoxic. Alternatively, the complex interactions between glia and neurons in organotypic cultures may conspire together to attenuate any neurotoxic effect of capsaicin by activation of endogenous neuroprotective cellular processes within the slice.

\section{Capsazepine is neuroprotective in slice cultures}

Our studies using the OGD model have shown that capsazepine is neuroprotective in that it prevents both changes in cell number and alterations in macroscopic synaptic function that normally occur in response to this insult. Taken at face value, these results could be interpreted as a neuroprotective action through antagonism of the $\mathrm{Ca}^{2+}$-permeable nonspecific cation channel $\mathrm{VR}_{1}$. However, when viewed in conjunction with the observation that capsazepine is still neuroprotective in hippocampal slices derived from $\mathrm{VR}_{1}$ knockout mice, it appears that capsazepine is acting through an alternative mecha$\operatorname{nism}(\mathrm{s})$ to $\mathrm{VR}_{1}$ antagonism to produce its neuroprotective effect. Furthermore, not only does $\mathrm{VR}_{1}$ not appear to be an essential component in OGD neurodegeneration, its sustained activation does not result in marked changes in neuronal excitability or cellular deterioration, because $10 \mu \mathrm{M}$ capsaicin, which is sufficient to maximally activate $\mathrm{VR}_{1}$ in sensory neurons (Bevan et al., 1992), had no overt effects on synaptic electrophysiology or cell viability.

Thus, if the neuroprotective action of capsazepine does not result from an interaction with $\mathrm{VR}_{1}$, how does capsazepine afford neuroprotection? The $\mathrm{VR}_{1}$ receptor, although clearly unique in its own right, does share many molecular and biophysical properties that are displayed by other members of the voltage-gated and ligandgated ion channel families. It is not surprising, therefore, that capsazepine has been reported to inhibit a variety of ligand- and voltage-gated ion channels that, like $\mathrm{VR}_{1}$, are cation permeable.

\section{AMPA and NMDA receptors}

Antagonism of NMDA receptors has been shown to be extremely effective in preventing OGD-induced neurodegeneration (Maier et al., 1995; Werth et al., 1998; Pringle et al., 2000). Likewise, blockade of AMPA receptors can afford neuroprotection (Strasser and Fischer, 1995; LoPachin et al., 2001). However, these are unlikely to be the target mechanisms that explain the neuroprotective effect of capsazepine because capsazepine did 
not affect AMPA or NMDA receptor-mediated synaptic transmission. The inactivity of capsazepine as a group I mGluR antagonist is also noteworthy because both mGluR1 and mGluR5 antagonists have been shown recently to prevent excitotoxic neurodegeneration (Bruno et al., 1999, 2000).

\section{Sodium and potassium channels}

Capsazepine inhibits both voltage-gated sodium and potassium channels (Kuenzi and Dale, 1996; Su et al., 1999). However, these nonspecific actions are observed at concentrations in excess of 10 $\mu \mathrm{M}$, which are 10 - to 100 -fold higher than the concentrations that afford significant levels of neuroprotection in the present study. Furthermore, we could not demonstrate any effect of capsazepine on TTX-sensitive voltage-gated sodium currents in our hippocampal organotypic slice cultures. Thus, it seems unlikely that modification of these cationic channels is a major contributing factor to the neuroprotective mechanisms invoked by capsazepine in the OGD model.

\section{Voltage-operated calcium channels}

Because the magnitude of OGD neurodegeneration is dependent on extracellular calcium, it is possible that inhibition of voltagegated $\mathrm{Ca}^{2+}$ channels could potentially provide a mechanism of neuroprotection. However, although capsazepine has been reported to inhibit voltage-activated calcium channels (Docherty et al., 1997), it is unlikely that this activity is responsible for its neuroprotective action because (1) the $\mathrm{IC}_{50}$ for capsazepine induced voltage-gated $\mathrm{Ca}^{2+}$ channel blockade is $1.4-10 \mu \mathrm{M}$, whereas the $\mathrm{IC}_{50}$ for its neuroprotective effect is $0.1-0.3 \mu \mathrm{M}$, and (2) studies using the high-voltage-activated calcium channel antagonists $\omega$-conotoxin MVIIC, which blocks $\mathrm{N}$ type as well as other presynaptic calcium channels, nifedipine, which blocks $\mathrm{L}$ type channels, and SB201823-A, which is a broad-spectrum calcium channel blocker, provided little or no protection against OGD insults in organotypic hippocampal cultures (Pringle et al., 1996).

\section{Nicotinic acetylcholine receptor}

Nonglutamatergic ligand-gated ion channels have also been implicated as targets affording neuroprotection. One in particular is the nAChR (Marin et al., 1994). However, although capsazepine has been shown to be active against this ligand-gated receptor, it acts as an antagonist (Liu and Simon, 1997), and it is generally accepted that nicotinic agonists, and not antagonists, afford neuroprotection (Dajas-Bailador et al., 2000). Furthermore, in our own studies, we showed that the broad-spectrum nAChR antagonist dihydro- $\beta$-erythroidine and the $\alpha 7 \mathrm{nAChR}$-selective antagonist $\alpha$-methylcaconitine suggest that antagonism of nAChRs does not protect against OGD-induced neurodegeneration.

\section{Hyperpolarization activated cyclic nucleotide modulated channel-1 channels}

An interesting and novel finding of this study, however, was that capsazepine inhibited the hyperpolarization-activated nonspecific cation channel-mediated current $I_{h}$. We believe that it is this activity that underlies the neuroprotective effects of capsazepine because (1) the concentration range over which capsazepine inhibited $I_{h}$ was similar to that which afforded functional neuroprotection, and (2) the specific $I_{h}$ blocker ZD-7288 exhibited a very similar profile of neuroprotection to that afforded by capsazepine in that it prevented cell death when applied either before or after the OGD insult. Recently, the specificity of ZD-7288 as a selective $I_{h}$ blocker has been called into question (Chevaleyre and
Castillo, 2002). However, in the current study, we are confident that its effects are related to inhibition of $I_{h}$ because it was effective in a concentration range that inhibits $I_{h}$, and, equally importantly, this range is well below that reported to inhibit glutamatergic synaptic transmission. That inhibition of $I_{h}$ is neuroprotective can be rationalized by the well documented observations that ZD-7288 hyperpolarizes hippocampal neurons and prevents concerted synchronized bursting of the form likely to produce neuronal damage.

\section{Concluding remarks}

Given the data presented in this study that rule out previously identified pharmacological activities of capsazepine as the site of action of its neuroprotective activity, we feel that it is justified to conclude that capsazepine mediates its neuroprotective effects, at least in part, through inhibition of $I_{h}$. That said, we cannot conclusively rule out the possibility that it may mediate part of its effects through (1) conjoint activation and/or inhibition of a number of cellular processes or (2) additional pharmacological properties yet to be discovered, e.g., block of an, as yet, undisclosed voltage-gated channel and possibly a member of the transient receptor potential channel family to which $\mathrm{VR}_{1}$ and hyperpolarization activated cyclic nucleotide modulated channel-1 channels are closely related (Caterina et al., 1997). This aside, that inhibition of $I_{h}$ provides neuroprotection is a particularly novel and interesting finding, not least because this mechanism is effectively neuroprotective when implemented either before or after the OGD insult. Most importantly, this pattern of activity is what is required to produce a useful therapeutic agent for stroke and other head trauma injuries as these patient groups are usually defined after the initial neurodegenerative insult when treatment is restricted to preventing the secondary damage that occurs after that induced by the insult itself.

\section{References}

Bevan S, Hothi S, Hughes G, James IF, Rang HP, Shah K, Walpole CS, Yeats JC (1992) Capsazepine: a competitive antagonist of the sensory neurone excitant capsaicin. Br J Pharmacol 107:544-552.

Bruno V, Battaglia G, Kingston A, O’Neill MJ, Catania MV, Di Grezia R, Nicoletti F (1999) Neuroprotective activity of the potent and selective mGlula metabotropic glutamate receptor antagonist, $(+)-2$-methyl-4 carboxyphenylglycine (LY367385): comparison with LY357366, a broader spectrum antagonist with equal affinity for mGlula and mGlu5 receptors. Neuropharmacology 38:199-207.

Bruno V, Ksiazek I, Battaglia G, Lukic S, Leonhardt T, Sauer D, Gasparini F, Kuhn R, Nicoletti F, Flor PJ (2000) Selective blockade of metabotropic glutamate receptor subtype 5 is neuroprotective. Neuropharmacology 39:2223-2230.

Caterina MJ, Julius D (2001) The vanilloid receptor: a molecular gateway to the pain pathway. Annu Rev Neurosci 24:487-517.

Caterina MJ, Schumacher MA, Tominaga M, Rosen TA, Levine JD, Julius D (1997) The capsaicin receptor: a heat-activated ion channel in the pain pathway. Nature 389:816-824.

Chard PS, Bleakman D, Savidge JR, Miller RJ (1995) Capsaicin-induced neurotoxicity in cultured dorsal root ganglion neurons: involvement of calcium-activated proteases. Neuroscience 65:1099-1108.

Chevaleyre V, Castillo PE (2002) Assessing the role of Ih channels in synaptic transmission and mossy fiber LTP. Proc Natl Acad Sci USA 99:9538-9543.

Dajas-Bailador FA, Lima PA, Wonnacott S (2000) The alpha7 nicotinic acetylcholine receptor subtype mediates nicotine protection against NMDA excitotoxicity in primary hippocampal cultures through a $\mathrm{Ca}^{2+}$ dependent mechanism. Neuropharmacology 39:2799-2807.

Davis JB, Gray J, Gunthorpe MJ, Hatcher JP, Davey PT, Overend P, Harries MH, Latcham J, Clapham C, Atkinson K, Hughes SA, Rance K, Grau E, Harper AJ, Pugh PL, Rogers DC, Bingham S, Randall A, Sheardown SA (2000) Vanilloid receptor-1 is essential for inflammatory thermal hyperalgesia. Nature 405:183-187. 
Docherty RJ, Yeats JC, Piper AS (1997) Capsazepine block of voltageactivated calcium channels in adult rat dorsal root ganglion neurones in culture. Br J Pharmacol 121:1461-1467.

Egert U, Schlosshauer B, Fennrich S, Nisch W, Fejtl M, Knott T, Muller T, Hammerle H (1998) A novel organotypic long-term culture of the rat hippocampus on substrate-integrated multielectrode arrays. Brain Res Brain Res Protoc 2:299-242.

Grant ER, Dubin AE, Zhang SP, Zivin RA, Zhong Z (2002) Simultaneous intracellular calcium and sodium flux imaging in human vanilloid receptor 1 (VR1)-transfected human embryonic kidney cells: a method to resolve ionic dependence of VR1-mediated cell death. J Pharmacol Exp Ther 300:9-17.

Greene JG (1999) Mitochondrial function and NMDA receptor activation: mechanisms of secondary excitotoxicity. Funct Neurol 14:171-184.

Hansen HS, Lauritzen L, Strand AM, Moesgaard B, Frandsen A (1995) Glutamate stimulates the formation of $\mathrm{N}$-acylphosphatidylethanolamine and $\mathrm{N}$-acylethanolamine in cortical neurons in culture. Biochim Biophys Acta 1258:303-308.

Hayes P, Meadows HJ, Gunthorpe MJ, Harries MH, Duckworth DM, Cairns W, Harrison DC, Clarke CE, Ellington K, Prinjha RK, Barton AJ, Medhurst AD, Smith GD, Topp S, Murdock P, Sanger GJ, Terrett J, Jenkins O, Benham CD, Randall AD, Gloger IS, Davis JB (2000) Cloning and functional expression of a human orthologue of rat vanilloid receptor-1. Pain $88: 205-215$

Jerman JC, Brough SJ, Prinjha R, Harries MH, Davis JB, Smart D (2000) Characterization using FLIPR of rat vanilloid receptor (rVR1) pharmacology. Br J Pharmacol 130:916-922.

Kuenzi FM, Dale N (1996) Effect of capsaicin and analogues on potassium and calcium currents and vanilloid receptors in Xenopus embryo spinal neurones. Br J Pharmacol 119:81-90.

Liu L, Simon SA (1997) Capsazepine, a vanilloid receptor antagonist, inhibits nicotinic acetylcholine receptors in rat trigeminal ganglia. Neurosci Lett 228:29-32.

LoPachin RM, Gaughan CL, Lehning EJ, Weber ML, Taylor CP (2001) Effects of ion channel blockade on the distribution of $\mathrm{Na}, \mathrm{K}, \mathrm{Ca}$ and other elements in oxygen-glucose deprived CA1 hippocampal neurons. Neuroscience 103:971-983.

Maccarrone M, Lorenzon T, Bari M, Melino G, Finazzi-Agro A (2000a) Anandamide induces apoptosis in human cells via vanilloid receptors. Evidence for a protective role of cannabinoid receptors. J Biol Chem 275:31938-31945.

Maccarrone M, Ranalli M, Bellincampi L, Salucci ML, Sabatini S, Melino G, Finazzi-Agro A (2000b) Activation of different lipoxygenase isozymes induces apoptosis in human erythroleukemia and neuroblastoma cells. Biochem Biophys Res Commun 272:345-350.

Maier CM, Sun GH, Kunis DM, Giffard RG, Steinberg GK (1995) Neuroprotection by the $N$-methyl-D-aspartate receptor antagonist CGP 40116: in vivo and in vitro studies. J Neurochem 65:652-659.

Marin P, Maus M, Desagher S, Glowinski J, Premont J (1994) Nicotine pro- tects cultured striatal neurones against $N$-methyl-D-aspartate receptormediated neurotoxicity. NeuroReport 5:1977-1980.

McIntyre P, McLatchie LM, Chambers A, Phillips E, Clarke M, Savidge J, Toms C, Peacock M, Shah K, Winter J, Weerasakera N, Webb M, Rang HP, Bevan S, James IF (2001) Pharmacological differences between the human and rat vanilloid receptor 1 (VR1). $\mathrm{Br} \mathrm{J}$ Pharmacol 132:1084-1094.

Mezey E, Toth ZE, Cortright DN, Arzubi MK, Krause JE, Elde R., Guo A, Blumberg PM, Szallasi A (2000) Distribution of mRNA for vanilloid receptor subtype 1 (VR1), and VR1-like immunoreactivity, in the central nervous system of the rat and human. Proc Natl Acad Sci USA 97:3655-3660.

Olah Z, Szabo T, Karai L, Hough C, Fields RD, Caudle RM, Blumberg PM, Iadarola MJ (2001) Ligand-induced dynamic membrane changes and cell deletion conferred by vanilloid receptor 1. J Biol Chem 276:11021-11030.

Pringle AK, Benham CD, Sim L, Kennedy J, Iannotti F, Sundstrom LE (1996) Selective N-type calcium channel antagonist omega conotoxin MVIIA is neuroprotective against hypoxic neurodegeneration in organotypic hippocampal-slice cultures. Stroke 27:2124-2130.

Pringle AK, Self J, Eshak M, Iannotti F (2000) Reducing conditions significantly attenuate the neuroprotective efficacy of competitive, but not other NMDA receptor antagonists in vitro. Eur J Neurosci 12:3833-3842.

Ray AM, Owen DE, Evans ML, Davis JB, Benham CD (2000) Caspase inhibitors are functionally neuroprotective against oxygen glucose deprivation induced CA1 death in rat organotypic hippocampal slices. Brain Res 867:62-69.

Sasamura T, Kuraishi Y (1999) Peripheral and central actions of capsaicin and VR1 receptor. Jpn J Pharmacol 80:275-280.

Smart D, Jerman JC (2000) Anandamide: an endogenous activator of the vanilloid receptor. Trends Pharmacol Sci 21:134.

Stella N, Schweitzer P, Piomelli DA (1997) A second endogenous cannabinoid that modulates long-term potentiation. Nature 388:773-778.

Stoppini L, Buchs LA, Muller D (1991) A simple method for organotypic cultures of nervous tissue. J Neurosci Methods 37:173-182.

Strasser U, Fischer G (1995) Protection from neuronal damage induced by combined oxygen and glucose deprivation in organotypic hippocampal cultures by glutamate receptor antagonists. Brain Res 687:167-174.

Su X, Wachtel RE, Gebhart GF (1999) Capsaicin sensitivity and voltagegated sodium currents in colon sensory neurons from rat dorsal root ganglia. Am J Physiol 277:G1180-G1188.

Szallasi A, Nilsson S, Farkas-Szallasi T, Blumberg PM, Hokfelt T, Lundberg JM (1995) Vanilloid (capsaicin) receptors in the rat: distribution in the brain, regional differences in the spinal cord, axonal transport to the periphery, and depletion by systemic vanilloid treatment. Brain Res 703:175-183.

Werth JL, Park TS, Silbergeld DL, Rothman SM (1998) Excitotoxic swelling occurs in oxygen and glucose deprived human cortical slices. Brain Res 782:248-254. 